\title{
Espaços da mulher
}

\author{
Beatriz Weigert \\ Universidade de Évora
}

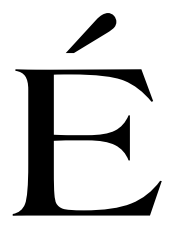

na década de sessenta que Maria Velho da Costa inicia a construção de seu espaço literário e nele instala O Lugar Comum, recanto especial da experiência feminina. Publicado em 1966, o livro traz cinco contos, cada qual contendo faces significativas da vida quotidiana. Havendo indicação da data e local da composição, alinham-se as narrativas "Exílio Menor" - Lisboa, Dezembro de 1962; "O Furto" - Sintra, Maio de 1965; "Thel" - Lisboa, Junho de 1964; "A Velada" - Sintra, Setembro de 1965; "O Lugar Comum" - Fevereiro de 1965. Compulsando as datas, registamos o primeiro texto em livro da autoria de Maria Velho da Costa. É "Exílio Menor".

Exílio? Menor? Porquê?

Este conto é o recorte de um dia na vida de uma colegial, e, já na abertura, o discurso orienta o leitor para o imaginário e interesses de criança. Depois, o pronome "ela" entrega a identificação do feminino.

Um narrador omnisciente acompanha Lurdes em suas vivências de escola e família, anotando-lhe as acções. Mas não só. Esse narrador indiscreto também devassa-lhe esconderijos: surpreende divagações distraídas em momento de lição e oração, esquadrinha a bagagem escolar, confisca tesouros de bolso e bolsa. E toma mesmo outras mais liberdades: ao descrever brincadeiras ruidosas ou atitudes reflexivas de Lurdes, ousa acrescentar informações, ditadas pelo saber próprio, dele mesmo, atestando o conhecimento maduro de narrador experiente que avalia e faz previsões.

Define-se assim, em psycho-récit ${ }^{1}$, uma dupla consciência, de vez que o narrador, assentado na consciência de Lurdes, não abdica da sua própria. Segue o percurso da menina, sim!, mas vai comentando os signos dispersos que recolhe. Transita pelo mundo objectivo e pelo mundo subjectivo da personagem, decifra-lhe inscrições do passado e emite juízos

${ }^{1}$ COHN, 1981. p. 37 e segs. 
valorativos sobre formação de carácter. Esse narrador vê os comportamentos atuais, não só como reflexo de uma vivência pretérita (tão habitual aos que na mais remota infância brincaram sós), mas também caminhando (com alguns elementos sedimentados e outros em transformação) em direcção ao futuro (Lurdes ainda gostava de baloiços... ela tinha já muito amor ...). Assim, a vida psíquica flui do passado ao presente e em projecção ao futuro.

O narrador arrebata um retrato em movimento, pontuando com os signos ainda e já o carácter em processo de incompletude / completude. Reforça-se, então, a identidade da personagem observada na abertura do conto: Lurdes está em crescimento (adolescens, adolescentis), nas hesitantes formas de uma puberdade infindável.

De facto, sabemos como se insere Lurdes nas faixas etárias da escola. Há o espaço das mais pequenas, e o das grandes. Isso significa que ela pertence a um quadro intermediário: ainda no prazer da correria e do baloiço, mas já na reflexão sobre os conceitos da vida, na desconfiança da palavra dos adultos, na divagação com as amigas sobre Deus ou a tristeza ou as pessoas grandes. A ambivalência ${ }^{2}$ é própria dessa fase de crescimento, em que as flutuações psíquicas reflectem a acomodação ao corpo novo que se fabrica, não sendo já o de criança, nem ainda o de adulto.

"Exílio Menor" segue esse movimento dual. Realiza incursões em espaços interiores e exteriores; faz projecções de imagens luminosas e escuras; possibilita confrontações entre o mundo das adolescentes e o mundo dos adultos. As acções obedecem ao pêndulo do relógio. O sinal horário da campainha estabelece o ritmo do dia das colegiais, regula o ritual, dando a marcação dos cenários (sala de aula-pátio / jardim-capelacasa). Nesse sentido, a valoração transita em gradações qualitativas, do espaço da natureza para o da cultura. Um é o espaço da exuberância, da agilidade, da voz, da cor, do brilho, da luz, do sabor. Do chocolate. O outro é o espaço do constrangimento, do desânimo, do silêncio, do escuro, do poço, do insosso. Da hóstia. De um lado lateja o corpo vivo cheio de sangue. Do outro, agoniza o corpo exangue nada de carne. Natureza e cultura arrematam-se, afinal, em convívio, num espaço da mais genuína privacidade: as aparas (de hóstia) se foram misturar (no bolso) às nódoas de sangue do joelho. Espaço íntimo da adolescência é esse bolso

\footnotetext{
${ }^{2}$ ABERASTURY, 1990. p. 15.
} 
resguardado da repreensão dos adultos. Ali no escondido, podem conviver os resíduos da seriedade quase sagrada (o pão da hóstia) e os da brincadeira desastrosa (o lenço com o sangue do joelho).

Essa dinâmica de oposições confirma o espírito combativo da adolescência. A polémica se estabelece na inviabilidade de harmonizar o desejo de liberdade com a necessidade de proteção ${ }^{3}$. As imagens desdobram simbolismos diurnos e nocturnos ${ }^{4}$. Os signos da competitividade e os da estabilidade confrontam-se. As acções de libertação reiteram-se no esforço de ultrapassagem ${ }^{5}$, em que a figura do pai é mancha que se supera em direcção à verticalidade até à culminância. $\mathrm{O}$ voo no espaço lúdico é o jogo de ascensão às alturas, tocando as mais altas ramadas, transpondo o muro e o portão de ferro ao encontro do reino desconbecido. O voo no espaço da escrita é o jogo da fantasia, exercitando a palavra, aprofundando significações, buscando a transcendência de um reino a vir.

O repouso da segurança realiza-se no desenho do ninho, aconchego materno, ambivalente na sua composição nutricional e sexual ${ }^{6}$. Perfume de mãe, a um tempo sedução e rejeição, aproximação e distanciamento, identificação e desconhecimento. Mulher: cúmplice e rival. Envolta em mistério! Ventre rico de transformações! Mulher-árvore recheada de líquidos ocultos lentos e grossos como mel, secretando a força potente que transforma fendas subtis (de letras) iniciais em rebordos grossos como beiços. Sentir humano equivalente ao sentir vegetal. Dor do joelho $=$ dor da árvore?

Misteriosa natureza! Secreto secretar! Humores íntimos transformam o corpo púbere, com a sexualidade a intumescer-se nos rebordos. O joelho sangra no picar do brinquedo. Porém a adolescência quer outro sangue. Sangue na perna, entre pernas. Sexualidade de mistérios! Inquietação! Desejo de conhecimento! Sonho e resposta! Acessos febris, que a infância não consumara, aproximam, agora, a luz de saber tudo, sem formas e sem mistérios. Descer para conhecer. Embrenhar-se no inconsciente e extrair dele uma decifração. Aprofundar-se para atingir o núcleo, para fruir as

\footnotetext{
3 ABERASTURY, 1990. p. 15.

${ }^{4}$ DURAND, 1989. p. 137.

${ }^{5}$ DURAND, 1989. p. 137.

${ }^{6}$ DURAND, 1989. p. 137.
} 
perplexas delicias da doce massa cremosa e esvair-se devagar. Uma potência intuída acrescenta-se como valência do corpo. O sonho traz a antecipação de uma serenidade por conquistar. Completa-se um percurso.

"Exílio Menor" realiza esse percurso da adolescência: narra a ambivalência, a convivência com o corpo, a busca do par sexual, a aquisição da identidade, a aspiração à transcendência. E a personagem, Lurdes, concretiza o movimento da própria literatura. Como texto literário, realiza-se em rebeldia, desafio e superação. Porém, é a escrita ninho gerador, continente que recebe e transforma. É ventre vibrante da pulsão erótica que deseja e cria no poder de aspirar um reino a vir.

"Exílio Menor", primeira produção de Maria Velho da Costa, é semente. É exílio secundado por outros: opções de protesto, solidão imposta ou escolhida, sacrifício dos sentidos, isolamento e recusa do mundo adulto. Mudez, cegueira, alienação, morte: Maina Mendes, Lúcialima, Ema/Sara. Comportamentos insólitos assinalam esses exílios menores ou maiores. E situações semelhantes vivenciam-se pelas personagens, substitutas de Lurdes, portando novos nomes. No entanto, revivem-se cenas, espaços, brinquedos, observações. Quadros e cenários recompõem-se de história em história. Lurdes, à janela, contemplando a paisagem antecipa Maina Mendes em cima da cadeira pesada de arrastar (Maina Mendes, p. 23). O vidro é topos recorrente (protetor/repressor) de observação do mundo exterior. Mas Lurdes também é Elisa, pequena e diante de uma carteira das que levantam a tampa, na admiração da turgência fecunda das árvores que abriam beiços no tempo às incisões do nome próprio (Casas Pardas, p. 142-143). E é Maria Eugênia cujos pés, ao baloiço, já tocam as mais altas pernadas da nespereira (Lucialima, p. 4849). Lurdes é Sara de Missa in Albis no seu gosto pela provocação do riso.

A intertextualidade, um dos recursos caros a Maria Velho da Costa, já está presente em "Exílio Menor", em que a iconografia religiosa, o Cristo do século XII, transpõe Lurdes para a esfera da criatividade, onde vai sonhando respostas. São experiências infantis que a memória impõe, e as meninas, desta ou daquela história, sabem recordar.

Seguindo "Exílio Menor" vem "O Furto", o quarto texto do livro. O título resume uma visão de mundo que contrapõe natureza e cultura. Trata-se da sonegação de uma experiência em plenitude, quando a sabedoria da natureza é substituída pelo avanço da técnica. Narra-se o sentimento de frustração da expectativa de viver o acto humano primordial. "O Furto" narra uma parturição. 
O texto divide-se em seis partes, conforme as interrupções da mancha gráfica, sinalizando as diferentes situações da personagem. A narração é feita em terceira pessoa por um narrador omnisciente, solidário. A história progride na sequência do trabalho de parto, até ao momento em que a mãe aconchega o filho nos braços. As acções da narrativa organizam-se em fases marcadas por três principais movimentos: primeiro, o da mansidão; segundo, o do combate; por último, o do descanso, identificado como alivio - porém - alivio triste.

O primeiro, a mansidão, rege-se em harmonia com a natureza: "O fluxo de água, apenas água, sem qualquer coloração ou odor, era abundante. Até seus pés nus, (...) via-a descer quase quente, alargar-se junto aos tornozelos em fios de silêncio doce." (p. 55)

O reino mineral, o reino vegetal e o reino animal fazem presença.

A água flui em curso natural. Jorra como fonte. É a água límpida, pura, matéria-prima perfeita, fecunda e singela ${ }^{7}$, mãe e matriz, plena de fertilidade. Simbolicamente, masculina e feminina aqui, na dupla representação vertical e horizontal. Como a chuva, associada ao céu-fogo: água masculina que fecunda. Como as nascentes, alargada como os lagos doces, água-plasma ${ }^{8}$ feminina, brotando quente do interior da terra grávida. Nessa simbologia, entra a valência do sangue, também vida e criação.

A água abundante jorra sobre os pés nus. Pés despidos plantam-se directamente ao solo, sem qualquer mediação. Nenhum atavio da cultura interpõe-se nesse contacto. A mulher integra-se na natureza como vegetal. Daí extrai a força que sustenta sua inteireza, sua verticalidade ${ }^{9}$. Enquanto o nó do pé $e^{-10}$, o tornozelo, evocando a agilidade das asas, concretiza o acto de chegada (ou partida). É movimento. Voa. Adequa-se às representações do livro e do conto: início e nascimento.

A fluidez da água, em sinestesia, combina tacto, audição e gosto, em manifestações de delicadeza e agrado. Fios de silêncio doce e fio sereno brotam do ventre que sente alojar em si um imenso sono. A água, sendo sorvida pela terra, ou deslizando na pedra, como onda breve, é companhia

\footnotetext{
7 CHEVALIER e GHEERBRANT, 1990. p. 16 e segs.

${ }^{8}$ CHEVALIER e GHEERBRANT, 1990. p. 21.

${ }^{9}$ CHEVALIER e GHEERBRANT, 1990. p. 694.

${ }^{10}$ CHEVALIER e GHEERBRANT, 1990. p. 888.
} 
teimosa e clara. Mais tarde, como companhia, interferem outros elementos. Então a harmonia do aconchego se rompe.

Anuncia-se o combate, segundo movimento do conto.

A invasão do estranho gera oposição em duas frentes. Uma corresponde à técnica: aos meios artificiais de pretender substituir a sabedoria da natureza. O aconchego transforma-se em impessoalidade: rostos sem olhos, fardas sem rosto, frieza que se estende aos objectos metálicos; o solo, evocado como terra e pedra, é chão vermelho; o líquido límpido torna-se líquido amarelo; o processo fluindo suave na ordem natural, recebe intromissão para ajudar. Assim, mais nada é reconbecível.

O irreconhecimento do exterior - Lá fora era noite, não sabia que tempo da noite - logo penetra o próprio corpo: a primeira dor deixou-a incrédula. E identifica-se a outra frente do combate: é o ventre que, antes serenado em mansidão de água, agora, como um pedaço de terra soergue fumegante petrifica(va)-se, lateja(va) em crescendo até atingir a solidez de um só músculo.

O pedaço de terra fumegante corresponde ao trabalho do fogo. É produto da fagulha de Eros que, alojado nas entranhas, transforma-se em matéria sólida, volume da pedra. É o fogo seminal ${ }^{11}$, concentrado no vaso alquímico, que se transforma. A fricção do volume petrificado, na ânsia de libertação, fumega. O princípio feminino, a água, e o princípio masculino, ofogo intimo, entram em combate.

As armas, no entanto, estão adestradas. As investidas são revidadas, passe a passe:

e era do ar e do modo como o sorvia, leve e parcamente, e de todo o demais corpo esforçadamente pacificado e inerte perante a ilha de carne em pesado combate entre seus flancos, era do sóbrio ar e pensamento que retirava a força de cumprir-se sem gritos (p. 62).

A atenção da consciência lúcida domina os tempos do corpo em luta. O ar sorvido é obediente ao rito ${ }^{12}$, a uma respiração alta perto dos olhos e de seu sorriso nos intervalos, no exercício de expiração-inspiração, sopro de vida-alma ${ }^{13}$, propicia a libertação da matéria sólida. A respiração absorve a voz, cala o grito. O sorvo do ar, ao invés de instante de repouso

\footnotetext{
${ }^{11}$ BACHELARD, 1989a. p. 53

${ }^{12}$ BACHELARD, 1990a. p. 243.

${ }^{13}$ BACHELARD, 1990a. p. 247.
} 
e distenção ${ }^{14}$, na situação vivida aqui, é momento de trabalho físico e concentração mental. O sopro é alento (anima), lucidez. É consciência aguda. É sensibilidade atenta a minúcias. As forças renovam-se neste ar puro, ritmadamente sorvido. São vencidos os assaltos da dor. Unos [...] ventre e rins obedecem ao comando do ar leve e parcamente sorvido como um vento leve passando em ritmo curto e fresco na boca. "O fogo se vai no vento" 15 , desloca-se o volume gerado. A grande bolsa de carne onde o filho avança (va) é convite de funda alegria. O medo recua, a criança vem. No entanto, a funda alegria fica adiada. Nova intromissão da técnica frustra a expectativa tão arduamente vivida.

Marca-se o terceiro momento do "Furto" - o alivio triste.

A pressão da máscara negra faz retraírem-se os sentidos. O domínio sobre os membros e a lucidez da percepção esfuma-se. Da máxima acuidade passa ao indevido sono. Essa é a dor maior. Aquela que o gás da pazfalsa impõe. A mulher drogada para sua dor, sente roubados os limites de sua carne. Os momentos trabalhadamente suportados não trazem ainda a recompensa. O filho chora longe. É distância fabricada por meios artificiais. Desbotada alegria! Queixa-se a mãe ao bebé: a mágoa de não haver estado com ele desde o início.

Neste parto, combinam-se os quatro elementos cósmicos. E "O Furto" corresponde àquilo que é roubado à natureza. Pertence à nãonatureza.

O ventre feminino é terra de onde brota a água. Terra e água, princípios femininos, onde a reprodução se realiza. Índices de abundância marcam-se. A água desperdiça-se. A mãe terra é pródiga. A personagem idealiza a re-utilização da água empapando a terra e com ela formando a massa. Ao mesmo tempo imagina essa água, ao invés de confundida com a terra em humus de massa, a deslizar em onda breve, confundida com outra água, água salgada, masculina, violenta - do mar.

A mansidão dessa água feminina, calma e profunda - lacustre ${ }^{16}$ abriga um imenso sono (o mítico Morfeu ${ }^{17}$, que toma forma (conforme

\footnotetext{
${ }^{14}$ BACHELARD, 1990a. p. 138.

15 BACHELARD, 1990a. p. 243.

${ }^{16}$ CHEVALIER e GHEERBRANT, 1990. p. 21.

${ }^{17}$ GRIMAL, 1992. p. 318.
} 
a derivação grega da palavra) humana para aparecer nos sonhos). Sono que desperta em violência. É fogo comprimido que acorda e se quer liberto do espaço exíguo, onde foi aprisionado. A terra, nas entranhas, alberga água e fogo. Soa a hora da libertação do fogo transformado em volume de pedra - preciosa? - O ar transporta o fogo. Lança-o de dentro para fora do ventre. O sopro do vento liberta o fogo. O volume sólido, petrificado no seio materno, rompe o espaço que o contém e salta. Fogo e ar, princípios masculinos, combinam-se: fecundação, luz.

O sorvo da natureza que prevê a luz, vê-se substituído, pelo gás da paz falsa que é alívio triste. E a mulher de obreira confiada que se quisera sente que tudo the havia sido furtado.

"O Furto" sintetiza o desejo da vida natural. Desde o início do conto indiciam-se os roubos: é o desperdício da água, fonte da vida, (encharcando panos e algodões); é a falta de isolamento para realizar o parto seu; são os meios artificiais a interferirem no processo natural (o líquido amarelo (não-água, não-pureza) para ajudare a máscara do gás negro).

Os signos da intimidade, a nostalgia da natureza revela-se em arrependimento:

Porque não se havia separado, ido a uma casa onde houvesse quartos negros e vazios como quentes furnas ou caixotes vastos, e dessa solidão sem luz, sem visitantes e auxílios mudos, sairia cansada e sangrenta [...] duma dor sua apenas, sairia suja e vacilante com seu filho nos braços [...] como se fosse a primeira de todas as mulheres? Viria de parto seu [...] de mulheres onde as fardas sem rosto são violação e furto. Porque não se recolhera a tempo? (p. 59)

O isolamento da vida primitiva é desejado para a efectivação do acto genésico. Como fêmea, ciosa de sua cria, a mulher idealiza o espaço selvagem, inculto, para parir em solidão: grutas/furnas: quartos negrose vazios, na comunhão da natureza. A treva identifica o espaço subterrâneo que não permite acesso, nem à luz. É garantia de intimidade, de abrigo, de proteção correlativa do regaço materno ${ }^{18}$. A tepidez e negrume do

${ }^{18}$ BACHELARD, 1990b. p. 94 e segs. 
ventre da mãe são garantias de segurança. O espaço privado significa a posse do mundo, onde Eva, a primeira de todas as mulheres, cansadae sangrenta, é dona da sua experiência, de seu trabalho e de seu filho, cria selvagem do seio da terra. Mãe e filho, isolados do mundo, resguardamse neste exílio sagrado.

Exílio sagrado da produção literária, em que a obra nasce no isolamento, solidão e silêncio! Será comum esse lugar, o primeiro de Maria Velho da Costa? Lugar de fala e promessa. Ritualização da vida, ritualização da escrita! A página é espaço sagrado onde, a cada utopia, a esperança se renova num batismo in albis.

\section{Referências Bibliográficas}

ABERASTURY, Arminda e colaboradores, Adolescência. 6. ed. Trad. Ruth Cabral. Porto Alegre: Artes Médicas, 1990.

BACHELARD, Gaston, A psicanálise do fogo. Trad. Maria Isabel Braga. Lisboa: Litoral Edições, 1989a.

. A água e os sonhos: ensaio sobre a imaginação da matéria. Trad. Antonio Pádua Danesi. São Paulo: Martins Fontes, 1989b.

. O ar e os sonhos: ensaio sobre a imaginação do movimento. Trad. Antonio de Pádua Danesi. São Paulo: Martins Fontes, 1990a.

- A terra e os devaneios do repouso: ensaio sobre as imagens da intimidade. Trad. Paulo Neves da Silva. São Paulo: Martins Fontes, 1990b.

A poética do espaço. Trad. Antonio de Pádua Danesi. São Paulo: Martins Fontes, 1989.

CHEVALIER, Jean e GHEERBRANT. Dicionário de símbolos: mitos, sonhos, costumes, gestos, formas, figuras, cores, números. Trad. Vera da Costa e Silva, Raul de Sá Barbosa, Angela Melim, Lúcia Melim. 2. ed. Rio de Janeiro: José Olympio, 1990.

COHN, Dorrit, La transparence intérieure: modes de représentation de la vie psychique dans le roman. Traduit de l'anglais par Alain Bony. Paris: Éditions du Seuil, 1981.

COSTA, Maria Velho da. "Exílio menor". In: O lugar comum. Lisboa: Morais, 1966. p. 7-52. 
COSTA, Maria Velho da. "O furto". In: O lugar comum, Lisboa: Morais, 1966. p. 55-77.

. Maina Mendes, 3. ed. Lisboa: Dom Quixote, 1993.

. Casas pardas, 3. ed. Lisboa: Morais, 1979.

. Lúcialima, 3. ed. Lisboa: O Jornal, 1986.

. Missa in Albis. Lisboa: Dom Quixote, 1988.

DURAND, Gilbert, Estruturas antropológicas do imaginário: introdução à arquetipologia geral. Trad. Helder Godinho. Lisboa: Presença, 1989.

GRIMAL, Pierre. Dicionário de mitologia grega e romana. Trad. Victor Jabouille. Lisboa: Difel, [1992].

\section{Resumo}

Este trabalho ocupa-se de dois contos de Maria Velho da Costa. Ambos pertencem a $\mathrm{O}$ Lugar Comum, obra inaugural da autora. Enquanto em um, o narrador observa o curso do dia de uma adolescente em "exílio" na escola; no outro, acompanha a experiência da parturição de uma jovem mãe em "furto" no hospital. Contudo, o discurso omnisciente não abdica da prerrogativa de alinhar conceitos: os do narrador e os da personagem. E a autenticidade dos sentimentos edifica-se em imagens que respondem ao simbolismo de suas estruturas, e à psicanálise dos elementos cósmicos.

\section{Résumé}

Ce travail étudie deux contes de Maria Velho da Costa, publiés dans son premier livre intitulé O lugar comum. Dans le premier le narrateur s'occupe à dévoiler la journée d'une adolescente em "exil" a l'école; dans l'autre, il envisage l'expérience d'acconchement d'une jeune mére em "vol" à l'hôpital. 